\title{
METHODOLOGY FOR EXPOSURE AND RISK ASSESSMENT IN COMPLEX ENVIRONMENTAL POLLUTION SITUATIONS
}

\author{
MARIA DE LURDES DINIS* AND ANTÓNIO FIÚZA \\ Geo-Environment and Resources Research Center (CIGAR), \\ Engineering Faculty, University of Porto, Rua Dr. Roberto Frias, \\ 4465-024, Porto, Portugal

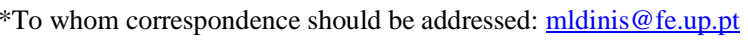

\begin{abstract}
Frequently environmental pollution results from different hazardous substances released in the environment, meaning that contaminated sites may have many different chemical sources and transport pathways. Problems concerning environmental pollution affect mainly physical, chemical and biological properties of air, water and soil. The relationships between the sources, exposure and effects of contaminants to human and ecological receptors are complex and many times are specific to a particular site, to certain environmental conditions and to a particular receptor. Often the methodology for exposure and risk assessment to environmental pollution is translated into sets of assessment questions. These questions are used to meet the needs of assessment, particular important in focusing the assessment during the problem formulation. Risk assessments vary widely in scope and application. Some look at single risks in a range of exposure scenarios, others are site-specific and look at the range of risks posed by a facility. In general, risk assessments are carried out to examine the effects of an agent on humans (Health Risk Assessment) and ecosystems (Ecological Risk Assessment). Environmental Risk Assessment (ERA) is the examination of risks resulting from technology that threaten ecosystems, animals and people. It includes human health risk assessments, ecological risk assessments and specific industrial applications of risk assessment that analyze identified end-points in people, biota or ecosystems.
\end{abstract}

Keywords: Risk assessment, exposure, hazard and environment.

L. Simeonov and M. Hassanien (eds.),

Exposure and Risk Assessment of Chemical Pollution - Contemporary Methodology, 111-132

(C) Springer Science+Business Media B.V. 2008 


\section{Introduction}

Environmental risk assessment refers to the quantitative and qualitative evaluation of the risk posed to human health and/or to the environment by the actual or potential presence and exposure to particular pollutants. The relationships between the sources, exposure and effects of contaminants to human and ecological receptors are the basis to risk assessment. Environmental risk tools are based on models that describe pollutant pathways in open environmental system and simulate or model the release of a hazard from a source to the environment. In the context of environmental pollution a site specific assessment is conducted to inform a decision concerning a particular location. As generic purpose it may determine appropriate soil cleanup levels at the site; establish water discharge permit conditions to meet regulation standards and investigate the need for emission standards for sources of hazard air pollutants (EPA, 2007). An accurate site-specific assessment requires knowledge of contaminant form and how it enters in the environment; environmental conditions affecting contaminant (meteorological conditions, soil chemistry, water and sediment chemistry, etc.); presence of plants or animals contaminant bioaccumulation; pathways and routes of exposure to human or ecological receptors and the effects of the contaminant in the target receptor (EPA, 2007). Risk assessments vary widely in scope and application. Some look at single risks in a range of exposure scenarios, others are site-specific and look at the range of risks originated by a facility (Fairman et al., 1998). In general, risk assessments are carried out to examine the effects of an agent on humans (Health Risk Assessment) and ecosystems (Ecological Risk Assessment). Environmental Risk Assessment (ERA) is the examination of risks resulting from technology that threaten ecosystems, animals and people. It includes human health risk assessments, ecological risk assessments and specific industrial applications of risk assessment that analyze identified endpoints in people, biota or ecosystems (Fairman et al., 1998). Although health and ecological risk assessment are two different types of risk assessment, both processes are conceptually similar (in fact, ecological risk assessment was developed from human health risk assessment), but have a differing historical development, regulatory and policy priorities. Applied industrial applications have been separated as many of these assessments do not look in isolation at people or ecological systems. They look at real situations and they are likely to include engineering risk assessments as part of the overall environmental risk assessments and may take an integrated approach to human and environmental risks (Fairman et al., 1998). Although risk assessment is extensively used in environmental policy and regulation providing the scientific basis for much legislation and environmental guidelines, the results of risk assessment are not 
often universally accepted. This is mainly due to problems concerning the availability and quality of data used in risk assessment, the interpretation of data and results of the assessment as well as the treatment of uncertainty (Fairman et al., 1998).

\section{Risk Assessment Methodology}

More specifically, an environmental risk assessment is an analysis of the potential for adverse effects caused by contaminants of concern from a site to determine the need for remedial action or to develop target levels where remedial action is required. It involves analyzing the sources of a release, the mechanisms of chemical transport and the potential health risks to receptors. Usually risk analysis focus on three categories of risk problem: i) source term risks: associated with the risk of an event occurrence that may result in a release to the environment (a landfill liner failure, inappropriate treatment of an effluent discharged in a stream, etc.); ii) pathway risks: address the likelihood of a certain exposure of an environmental receptor to a hazard following an initial release (dispersion of a plume downwind of a stack, movement of a plume in groundwater towards to a receptor point, etc.); iii) the risks to harm the receptor that might occur as a result of the exposure (adverse health effects as a result of exposure to hazard gaseous contaminants or drinking water polluted).

Often the methodology for exposure and risk assessment to environmental pollution is translated into sets of assessment questions throughout the several stages of risk assessment (planning and problem formulation, exposure analysis and interpretation and risk characterization) (EPA, 2007). These questions are used to meet the needs of assessment, particular important in focusing the assessment during the problem formulation.

The planning and problem formulation stage provides an opportunity for initial consideration of the contaminant characteristics and their chemistry. These considerations, along with other aspects of the assessment, contribute to the development of a conceptual model that gives the important elements of risk assessment. The next step should provide information about the exposure and the consequence effects. Tools and methods should be used to conduct a specific analysis of these two processes resulting in a receptor exposure assessment and a stressor dose-response assessment. Interpretation and risk characterization involves risk estimation, uncertainty analysis and risk description. The final step is communicating results to risk managers in order to carry out the risk management, by the application of the assessment results, to define management options and communicate them to the interested parties (EPA, 2007). 


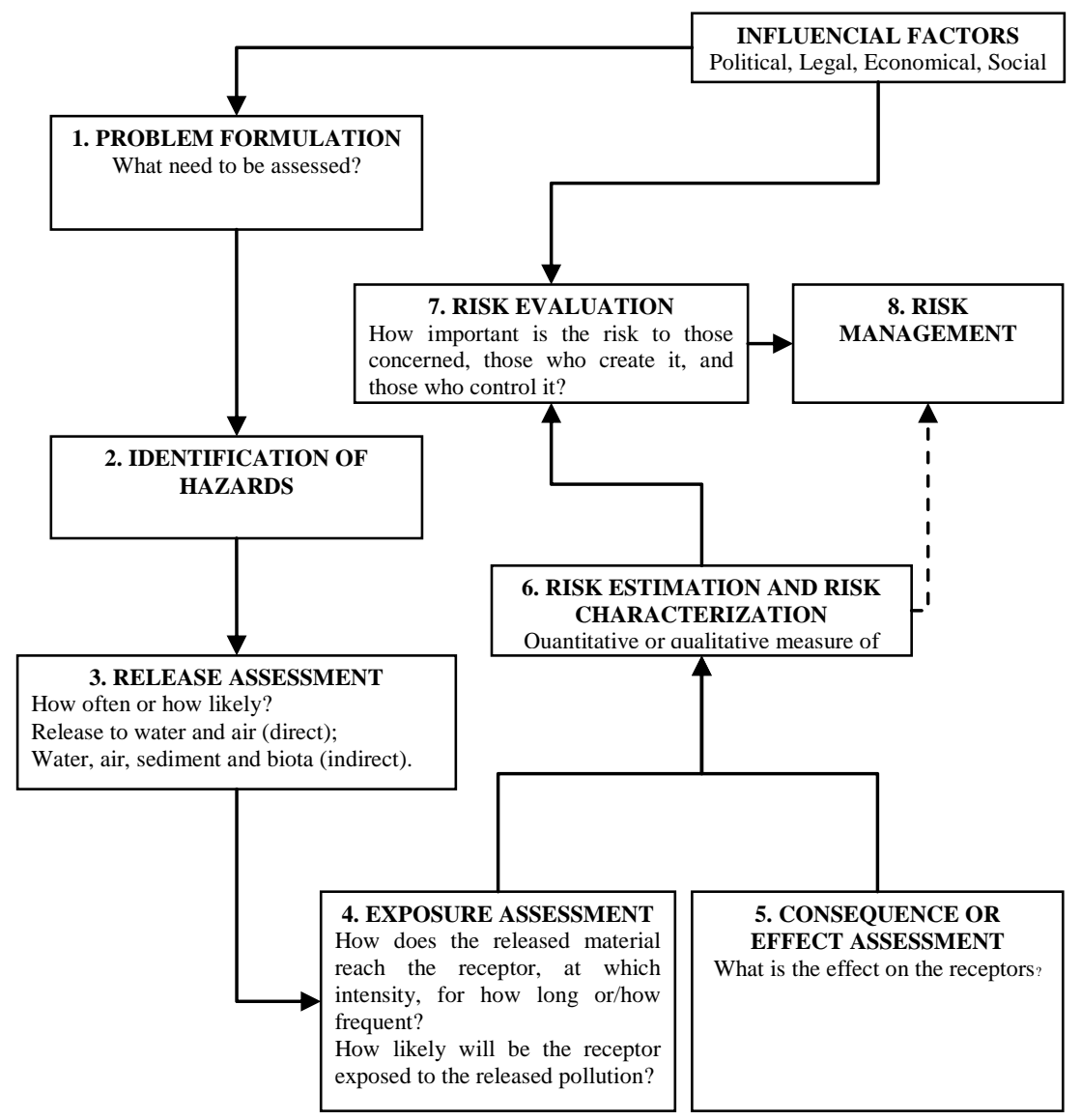

FIGURE 1: General key tasks in a environmental risk assessment (Fairman et al., 1998).

There are several unifying principles underlying all risk assessments but to carry out a environmental risk assessment, six steps should be followed as guidelines (Fairman et al., 1998) (Figure 1):

i) Problem formulation (provides initial consideration of contaminant characteristics and their chemistry);

ii) Hazard identification (what chemicals are present and are they likely to be toxic?);

iii) Release assessment (sources and rate releases);

iv) Exposure assessment (who is exposed, at what concentration, how often and for how long?);

v) Consequence or effect assessment (how is it toxic and at what exposure levels and what is the effect on the receptors); 
vi) Risk estimation and characterization (what does the risk assessment tell us about the situation and what are the risks, quantitative or qualitative).

Environmental risk assessment is also likely to include a seventh step given by risk evaluation defining how important is the risk to those affected, those who create it, and those who control it.

This step has laid down in the European legislation of new and existing substances (Fairman et al., 1998). The conclusions made in the risk characterization and/or risk evaluation are used as input for risk management in order to come up with an answer to which actions should be taken and how should the remaining risks be handled. Each one of this step will be discussed in detail in the following sections.

\subsection{PROBLEM FORMULATION}

In the first step the problem must be formulated and certain tasks must be clear before the assessment proceeds. These tasks should be based on (EPA, 2007): "What are we actually attempting to assess? What is the risk source? Is it a single chemical, an industrial plant or a process such as transportation? Are we concerned with the production, use or disposal of the hazard?" The risk source will generate hazards that may be released into the environment contributing to the transport, transfer and fate processes through the atmosphere, subsoil, underground and superficial aquatic systems, leading to the contamination of new environmental sub-compartments.

Also one should be point out the reasons why we are carrying out the risk assessment; which hazards should we include in the assessment; if it is based on regulatory standards to determine the "acceptable risk" or if regulatory and policy frameworks are being used to identify the most relevant end-points (EPA, 2007). During the problem formulation stage the following planning and scoping activities should also be included (EPA, 2007):

- Define the geographic scale and scope of the assessment;

- Identify potentially exposed populations and sensitive subpopulations;

- Characterize exposure pathways and exposure routes that will represent the conceptual model;

- Describe how exposure will be assessed;

- Determine how the hazard and the receptor's dose-response will be assessed;

- Describe how risks will be characterized. 


\subsection{HAZARD IDENTIFICATION}

Hazard identification involves the identification of those agents that could possibly cause harm to the receptor (people, organisms or ecosystems), specifying how this harm could occur.

The methods by which hazards are identified depend on the nature of the hazard and may include toxicological testing, examination of accident rates and epidemiological studies. There is a wide range of hazard identification techniques used in all types of risk assessment, but in particular for industry the most applicable resume to four of these techniques (Fairman et al., 1998):

- What if technique: brainstorming examinations of a process or a procedure, carried out in a small team with a chairman asking questions. The analysis considers the results of unexpected events that would produce an adverse consequence;

- Checklists technique: specify those components of a plant which requires a safe design. This technique uses data from industry, past accidents and expert judgements;

- Fault trees analyses: diagram that illustrates combinations of failures that will cause one specific failure or interest, the "top event"; the root is the main event and possible causes of the event are traced back to several initiating events;

- Event trees analyses: evaluates the potential for an accident as the result of a general equipment failure or process malfunction, known as the initiating event.

The hazard identification in the environment will include the phases of sampling and analyses to determine if the chemical may be toxic, to model the chemical fate and transport, to know how the contaminant or chemical may move through the environment to develop a conceptual site model, organize information regarding contaminants and chemicals and potential transport to people. For the conceptual model several inputs will be needed in order to gather information about the transport of contaminants and chemicals, the target exposed population and the way exposure changes in time. At last, we should analyse what information is missing; this last step is important to evaluate how realistic is the conceptual site model. In summary, the conceptual model lays out a series of working hypotheses about how the contaminant(s) of concern might move through the environment to cause adverse effects in humans or ecological systems. These hypotheses are examined through data analyses, models or other predictive tools, to determine the probability and magnitude of the occurrence of unwanted effects. 


\subsection{RELEASE ASSESSMENT}

A release assessment involves the identification of the risk potential source to introduce hazardous agents into the environment. This may be descriptive or involve the quantification of the release. It should identify the types of releases, its mechanism, the amount released, timings and probabilities of the release occurrence and a description of how these attributes might change in space and in time as a result of various actions or events (Fairman et al., 1998). The likelihood or probability of a release of hazards in a non-quantitative way may be given by "Expert judgment"; based on the results of the hazard identification. The likelihood is divided in different categories in terms of expressions such as: likely, may occur, not likely and very unlikely (Wilcox et al., 2000).

\subsection{EXPOSURE ASSESSMENT}

Exposure assessment is probably the most variable aspect of the risk assessment process. This is the reflection of a variety of contributing factors such as several exposure pathways, the unique nature of ecosystems, fauna and flora together with differing methodologies for exposure assessment as well as differences in dose response extrapolation methodology; for all these reasons, the exposure assessment is a critical element of the risk assessment (EPA, 2007). The assessment phase is the process of estimating exposure and understanding the dose-response relationship between the receptor and the contaminant. It should include a description of intensity, frequency and duration of exposure through the various exposure compartments, routes of exposure and the identification of the potential receptors exposed and a prevision of how these factors might change as a result of various actions or events and also with time. The exposure assessment step requires the use of monitoring data, exposure modelling techniques and also mapping models. Most of the time, exposure is determined in terms of the predicted environmental concentration, which is calculated on both local and regional spatial scales from monitoring data, when available, or by using realistic worst-case scenarios. If this information is not available, estimative may result from exposure models. Dispersion modelling is one approach to quantify the spatial extent of exposures to the wider environment from a point or area source.

The data and models used should be critically examined to ensure that they are appropriate to the level of the assessment results. The aim of this stage is to produce a complete picture of how, when, and where the exposure occurs or has occurred, by evaluating sources and releases and the extent and pattern of contaminant contact with humans or ecologically relevant biota. 
As a check procedure for this step, we should be able to answer to these questions: who is exposed? (is it an adult, a child or special populations with special characteristics?); how are they exposed? (is it through ingestion, inhalation or skin contact?); what is the concentration of chemical to which they are exposed in air, water or soil?; how often are they exposed? (days per year and the number of years exposed).

\subsection{CONSEQUENCE OR EFFECTS ASSESSMENT}

A consequence assessment analyzes the effects of the release or the production of the hazards to the specified receptors, and it involves quantifying the relationship between specified exposures to the hazard, health and the environmental effects of those exposures. The effects examined for human health are usually mortality or morbidity. The effects observed in ecological systems are much more varied and few defined end-points exist at present. The data for consequence assessment are mostly based on toxicity and ecotoxicity testing, epidemiology and dose-response models (Fairman et al., 1998). A doseresponse curve will give the relationship between the exposure to (or intake of) a hazardous agent and its toxicological (or chemical, or physical) effect on the receptor.

The consequence assessment should describe how the effects are elicited, link them to the receptor at greatest risk and evaluate how they change with varying exposure levels. The analysis addresses the veracity that effects may occur or are occurring as a result of exposure to the contaminant of concern, and that linkages between measured effects and assessment endpoints can be made (this is especially important for ecological risk assessments).

Taken as example an ecological assessment, the consequences or effects can be estimated in terms of the Predicted No Effect Concentration (PNEC) (based on EC Directive 93/67/EEC). Different PNEC values need to be derived for the relevant compartments of interest (water, sediments and biota compartments). Ecotoxicity tests will generate the PNEC values. The ecotoxicity available data are used to derive a No Observed Effect Concentration (NOEC) or a Lowest Observed Effect Concentration (LOEC) (Fairman et al., 1998).

As a check procedure during this step, we should be able to answer to these questions: What toxicity data are available? Acute or chronic effect? Or both? Does it have a carcinogenic or a non-carcinogenic effect? Or both? We should consider the effects of multiple chemicals (multiple nonlethal effects can still have an adverse impact on human health) and consider the route of exposure (effects can be "route of exposure" specific). 


\subsection{RISK CHARACTERIZATION AND ESTIMATION}

Risk characterization and estimation consists of integrating the results from the release assessment, exposure assessment and consequence assessment to produce measures of environmental risks. It is the final phase of the risk assessment and is the culmination of the planning, problem formulation and analysis of predicted or observed adverse effects. This may include an estimate of how many individuals experienced the health effects over time or measures indicating environmental damages as well as the uncertainty involved in these estimates; it should include and report an uncertainty analysis (Fairman et al., 1998).

The process of interpreting and integrating the information on hazard and exposure to provide a practical estimate of risk is complex and may involve determining what an acceptable risk is and how risk should be managed. As a check procedure during this stage we should be able to know what is the likelihood of harm following exposure to this contaminant or chemical in this specific situation, identify the receptors and exposure pathways of most concern, provide a numerical estimate of risk, identify key uncertainties in this estimate and compare the numerical estimate of risk with a previously determined risk goal.

We also should be aware of what does risk assessment not tells us such as whether risk is "acceptable", whether risk is equitably distributed across population or predictions regarding personal or individual risk.

Risk assessment is one part of a decision making process to manage hazards; science determines likelihood of effect but risk management determines whether and how the risk should be addressed; it is a decision making process to determine whether to take action for an identified risk.

The European Union practice on risk characterization involves the calculation of the PEC/PNEC ratio which should be calculated for all relevant endpoints. If the PEC/PNEC is less than 1, the substance of concern is considered to present no risk to the environment and there is no need for further testing or risk reduction measures. But if this ratio cannot be reduced to below 1 by refinement of the ratio (by gathering of further information and further testing), risk reduction measures are necessary (Fairman et al., 1998).

Sometimes a quantitative risk assessment approach can not be carried out (no PEC or PNEC can be properly calculated). In these cases, a qualitative risk assessment can be used as an alternative in which the risk characterization shall include a qualitative evaluation of the likelihood that an effect will occur under the expected conditions of exposure. These results can be used as a base to prioritize risk reduction measures (Fairman et al., 1998). 


\subsection{RISK EVALUATION}

Risk evaluation represents the evaluation of what risk assessment actually means in practice. What is the significance or value of the identified hazards and estimated risks? Risk evaluation deals with the trade-off between the perceived risks and benefits. This will include the public perception of the risk and the influence that this will have on the acceptability of risks decisions; it may take account of these perceived risks and benefits and incorporate them in the final risk assessment. On its turn, the public perception of risk depends on the economic, social, legal and political context in which the affected and/or concerned population lives (Fairman et al., 1998). The results from this risk evaluation may serve as an input to the risk management process. Based on the acceptable level of risk, eventual choices of action are determined to achieve the desired level of risk; if a system has a risk value above the risk acceptance level, actions should be taken to address concerned risks and to improve the system though risk reduction measures. Risk management decisions or actions may result in: i) no action at all, ii) implementation of information programmes; iii) economic incentives; iv) establish ambient standards; v) pollution prevention; vi) chemical substitution and/or chemical ban.

\subsection{UNCERTAINTY}

Uncertainty is inherent to all risk assessments. It is important to assess the magnitude of the uncertainty to determine the "relevance" of the quantified risk. Risks associated with a specific risk source and receptor, under pre-specified surrounding conditions, will be expressed in terms of a range (with a lower and upper bound) rather than a single figure. Knowing the uncertainty is also important to ensure that the input of the results into the risk evaluation step is realistic and thus to ensure that appropriate risk management decisions are made (Calewaert, 2006). Uncertainty can arise from several potential sources (Calewaert, 2006):

- Uncertainty inherent to methods used in each of the ERA steps: choice of model, assumptions made in used models, uncertainties related to the model structure itself as the lack of confidence that the mathematical model is an adequate representation of the assessment problem;

- Uncertainty related to the collected data and parameters: gaps in historic/recent data, use of data from other situations and extrapolations to fill out gaps, variability of a model parameter from its true heterogeneity over space and time, uncertainty of a model parameter resulting from the lack of information or knowledge about its true value; 
- Uncertainty of the analyst: interpretation of ambiguous or incomplete information, human error, uncertainty of how an assessor translates a real or forecasted situation in a given model.

Quantifying all sources of uncertainty is difficult. Methods for estimating the uncertainty are for example statistical analysis (for uncertainty related to data and parameters models), expert judgment (for uncertainty related to models) and sensitivity analysis (for uncertainty related to future trends). Uncertainty should be assessed for each one of the ERA steps.

\section{Risk Assessment Application to a Case Study}

\subsection{APPROACH OVERVIEW}

This section describes the methodology applied to calculate lifetime cancer incidence risk and non-carcinogenic health effects resulting from exposure to radionuclides and chemicals released from a contaminated site during a certain period of time. This approach uses current measures of radionuclides and chemicals in the environment media that individual members of the public may come in contact with, or be exposed to, during their daily activities while living near by the contaminated site. Radionuclide or chemical intake by humans is calculated using the average concentrations at the exposure site and applying typical intakes, such as a breathing rate or a water ingestion rate, associated with appropriate exposure parameters.

Carcinogenic risk or non-carcinogenic effects are estimated by multiplying the radionuclide or chemical intake or exposure, by the respective cancer risk or health-effects factor that relates the human risk to the amount of hazardous substances that the receptor takes into the body. This refers to a specific exposure period, therefore concentrations used for the radionuclide and chemical in environmental media should represent the exposure concentration over the same period of time considered.

A generic environmental media in which humans may be directly exposed or may generate an indirect exposure are: i) Air; ii) Groundwater; iii) Surface water; iv) Soil (surface and subsurface); v) Sediments; vi) Fish; vii) Food crops (leafy and non-leafy, vegetables, grains, fruits); viii) Vegetation (mainly pasture grass) and ix) Animal products (milk, meet, eggs, etc.) (EPA, 1998).

The methodology requires concentrations of radionuclides and chemicals in air, surface water, and groundwater and, in some cases, in soil and sediments. These concentrations may represent measured or modeled values. Models developed previously were used to estimate radionuclide or chemical concentrations in soil and biota, as well as concentrations in vegetation and in 
milk, from radionuclide or chemical concentration in air, surface water and groundwater. The endpoints of this approach is the annual incremental lifetime excess carcinogenic risk and a hazard quotient based on the annual noncarcinogenic effects for persons living, working and recreating in the model domain or in the study area for the a given exposure period (Rood, 2003).

The risks and health effects are calculated separately for each individual source of radionuclides and chemicals. This approach is designed to be general in nature and capable of considering almost any exposure scenario. Not all pathways included in this study may be important in terms of risk. However, the approach should be able to address each pathway quantitatively in order to assess its potential importance in terms of overall risk. Intake and exposures implicit refer to the various locations of exposure as well as to the fraction of time spent at each location. Risk from each exposure medium is calculated separately and then summed across all exposure media, exposure pathways and materials of concern. Risks are also summed separately for radionuclides, carcinogenic chemicals and non-carcinogenic chemicals. The final risk value is then determined.

This example intends to focus on the risk assessment methodology; the exposure models have been developed and published already (Dinis and Fiúza, 2005; 2006; 2007). Exposure scenarios definitions, exposure scenario parameters and parameters specific to radionuclides and chemical transport in soil and biota are not covered in this study.

\subsection{SITE CHARACTERIZATION}

As a reference site to apply the risk assessment methodology, a contaminated site from a former Portuguese uranium mine was selected. This mine was located in the central part of Portugal and it was exploited for almost a century, first for radium production (1913-1944) and then for uranium concentrates production (1951-2000). The mine is surrounded by small houses and country houses, with most of the local population living in a village within about $2 \mathrm{~km}$ from the mine. A tailing disposal is located near the mine; the liquid effluents, after neutralization and decantation, were discharged into a streamlet (Pantanha) flowing to the Mondego river (Bettencourt et al., 1990).

The contaminated site represents an area of 13,3 ha and until a very recent past radionuclides and chemicals have been released to the air, soil, surface water and indirectly to groundwater as a result of routine operations, accidents and waste disposal practices. Presently, a rehabilitation plan based on an in-situ reclamation scheme to promote the confinement of the tailings materials is under implementation as well as a wastewater treatment system implemented in the mining area (Nero et al., 2005). 


\subsection{ENVIRONMENTAL MEDIA CONSIDERED}

An environmental medium is defined as a discrete portion of the total environment that may be sampled or measured directly such as soil, sediment, groundwater, surface water or air (Rood, 2003). Environmental media considered in this study that humans may be exposed or consume are: Air; Groundwater; Soil; Food crops; Animal products.

\subsection{EXPOSURE ROUTES}

An exposure route is the manner through which a material of concern comes into contact with a human receptor (Rood, 2003). Exposure routes that may be considered in this methodology are: Inhalation; Ingestion; Dermal contact with soil and water; Irradiation from air; water, soil and dry sediments (radionuclides only).

\subsection{EXPOSURE PATHWAYS}

An exposure pathway is the course that a substance of concern takes from its source (where it began) to its end point (where it ends), and how people can come into contact with (or get exposed to) it. An exposure pathway can be divided in five simpler components: i) a source of contamination (such as an abandoned facility); ii) an environmental media and transport mechanism (such as movement through groundwater); iii) a point of exposure (such as a private well); iv) a route of exposure (eating, drinking, breathing, or dermal contact), and $v$ ) a receptor population (people potentially or actually exposed). When all five parts are present, the exposure pathway is termed a completed exposure pathway. All exposure pathways begin with a release from a source to an environmental medium. Sources are related to releases, discharges, or disposal to air, water and soil or sediment. These sources can contribute with materials of concern to four transport media (air, infiltrating and saturated groundwater, surface water and three static media (surface soil, fluvial sediment and subsurface soil). A transport media is an environmental medium where transport (advection, dispersion) and transfer (sorption, deposition, resuspension) processes are applied. A static medium is defined as an environmental medium where only transfer processes occur (Rood, 2003).

The following components of the exposure may be considered in this methodology:

- Source term: Atmospheric releases; Solid waste (tailings); Liquid waste (effluents). 
- Environmental media: Air (physical transport as advection and dispersion); transfer between media can occur - transport media; Surface soils (transfer between media can occur but transport within the medium is not considered - static medium); Animal products (environmental medium for biota; transport within the media is not considered).

- Human exposure routes: Ingestion; Inhalation; External radiation; Immersion; Dermal contact.

- Transfer processes: Deposition; Leaching; Irrigation; Ingestion by animals; Resuspension; Root uptake; Sorption (adsorption + absorption); Surface runoff; Biota transfer processes (absorption + translocation); Volatilization; Weathering.

The intake or exposure from each exposure route is multiplied by an appropriate factor relating intake or exposure to risk. The sum of risk from all exposure routes yields the total risk incurred from all exposure pathways considered for each substance of concern (Ingestion + Inhalation + Immersion + Dermal contact + External radiation $=$ Total risk $)$.

\subsection{CONCENTRATIONS AT POINTS OF EXPOSURE IN EACH ENVIRONMENTAL MEDIA AND EXPOSURE SCENARIO DEFINITION}

As a starting point it is assumed that there are measured or modeled concentrations of radionuclides and chemicals in environmental media. Concentrations in air, surface water or groundwater transport media are required. Transfer of radionuclides and chemicals from a transport media to static media (soil and biota) were performed in the modeling work developed before and published (Dinis and Fiúza, 2007). Concentrations are averaged over the exposure period and are intended to represent contributions from the contaminated site only. The exposure scenario is composed by a group of exposure pathways that define: i) location of points of exposure, duration of exposure and the individual reside, works, or activities in the study area; ii) environmental media that the individual contacts with and iii) estimate the quantity that is taken from the media into the body or that comes in contact with the body (Rood, 2003). The location may be defined in terms of a point coordinate. In this point, the receptor may breathe contaminated air, receive external exposure from gamma-emitting radionuclides in soil, fluvial sediments, consume water from a private well water supply, intentionally or unintentionally consume surface water, intentionally or unintentionally ingest contaminated soil, have contact direct with contaminated soil or be immersed in contaminated surface water or groundwater. Additionally, the receptor may consume homegrown garden products or milk from a backyard cow. 
Generically, some basic assumptions, limitations and principles involve the definition of all exposures pathways that make up the exposed scenarios. The mainly assumptions are:

- Receptor's daily activities occur in the study area (lives, work and recreates);

- The receptor may consume water from a private well; groundwater or surface water may also be used to irrigate crops and livestock;

- Risks endpoints include carcinogenic risk and non-carcinogenic effects calculated and discussed separately for radionuclides and chemicals according to the respective exposure pathway. Specific health-effects estimates include: incremental lifetime cancer incidence risk from radionuclides; incremental lifetime cancer incidence risk from chemicals and non-carcinogenic effects from chemicals.

- The total risk calculated represents the risk originated from the considered exposure period.

Generally, equations of cancer risk and non-cancer effects are set in terms of total risk. For this study, however all components of cancer risk or non-cancer effects are calculated and discussed separately.

In the following sections only some of the possible exposure pathways will be covered. Also different scenarios will be considered to show how to calculate the risk in different exposure scenarios.

\subsection{RISK CALCULATION}

For each of one of these cases we will consider only the internal exposure by inhalation and ingestion. No external exposure due to external radiation was considered. For internal exposure the total risk will be the sum of the risk by inhalation, soil ingestion, water ingestion and foodstuff ingestion. The contaminants of concern considered are radon (Radon-222), radium (Radium226), arsenic (inorganic As) and beryllium (Be).

We adopted as an acceptable risk the values below a Health Quotient (HQ) of 1 for non-carcinogens and below an Incremental Lifetime Cancer Risk (ILCR) of one in a million for carcinogens $\left(10^{-6}\right)$ (EPA, 1995).

\subsubsection{Incremental Lifetime Cancer Risk Incurred by Radionuclides Exposure}

\subsection{1.a. Radon Inhalation}

Radon-222 is a radioactive gas released during the natural decay of thorium and uranium, which are naturally occurring elements found in varying amounts in rock and soil. Radon-222 decays into radioactive elements, two of which, 
polonium-218 and polonium-214, emit alpha particles, which are highly effective in damaging lung tissues. These alpha-emitting radon decay products have been implicated in a causal relationship with lung cancer in humans. Lung cancer due to inhalation of radon decay products constitutes the only known risk associated with radon. However, not everyone exposed to elevated levels of radon will develop lung cancer, and the amount of time between exposure and the onset of the disease may be many years. Outdoors radon poses significantly less risk than indoors because it is diluted to low concentrations and dispersed in the air. In the indoor air environment, however, radon can accumulate to significant levels. Reduced ventilation may enable radon and its decay products to reach levels that are orders of magnitude above the outdoors levels. The magnitude of radon concentration indoors depends primarily on a building's construction and the amount of radon in the underlying soil. Many large scale studies have been conducted throughout the world to assess the indoor radon problem. In most common scenarios, the inhabitants go to work in day time so windows and doors are kept closed during this period. In the contaminated site considered there are several cases of houses constructed with mining waste material leading to high radon indoor levels. Radon in indoor air was measured in homes near the site and radon concentrations in the outside air were measured in the vicinity of the contaminated site (Falcão et al., 2005).

The critical receptor considered in this study is represented by farmers from the small farms in the vicinity of the site, for whom time not spent in their houses is likely spent outdoors; the following scenario suppose that the receptor spend $12 \mathrm{~h} /$ day during all year inside the house and $8 \mathrm{~h} /$ day, 5 days per week, outdoor working in open-air farm activities. The expression to estimate the cancer risk incurred by indoor radon inhalation is $\left(\mathrm{R}_{\mathrm{Rar}, \text { inh }}\right)(\mathrm{Rood}, 2003)$ :

$$
\mathrm{R}_{\text {Rair, inh }}=\mathrm{C}_{\text {air }} \cdot \mathrm{BR} \cdot \mathrm{RC}_{\text {air, inh }} \cdot \mathrm{E}_{\mathrm{f}} \cdot \mathrm{f}_{\text {eq }}(1)
$$

where $\mathrm{C}_{\text {air }}=381 \mathrm{~Bq} / \mathrm{m}^{3}$ (Falcão et al., 2005) is the radon concentration in the indoor air; $\mathrm{BR}=17,8 \mathrm{~m}^{3} / \mathrm{d}$ is the inhalation or breathing rate at the exposure location (EPA, 1999); $\mathrm{RC}_{\text {air,inh }}=4,86486 \times 10^{-10} \mathrm{~Bq}^{-1}$ is the cancer slope factor for radon inhalation (EPA, 1995); $\mathrm{E}_{\mathrm{f}}=183 \mathrm{~d} / \mathrm{year}$ is the indoor exposure frequency and $\mathrm{f}_{\mathrm{eq}}=0,4$ is the equilibrium factor for radon decay products (EPA, 1997).

The resulting annual cancer risk from indoor radon inhalation is $2,42 \times 10^{-4}$. This shows that indoor radon poses a risk of one in ten thousand $\left(10^{-4}\right)$. This value can be multiplied by 75 years to calculate the lifetime risk of lung cancer (ages 40-85) which yields 0,018 (Khan, 2000). To estimate outdoor radon inhalation risk we should use the radon outdoor concentration, $\mathrm{C}_{\text {air }}=122 \mathrm{~Bq} / \mathrm{m}^{3}$ (Falcão et al., 2005) and an outdoor exposure frequency of $87 \mathrm{~d} /$ year (8h/day, 5 days per week, 52 weeks per year) in the above equation. The resulting annual 
cancer risk from outdoor radon inhalation is $3,68 \times 10^{-5}$. This corresponds to a lifetime risk of lung cancer for an average life expectancy of 75 years of 0,003 (EPA, 1997).

\subsection{1.b. Radium-226 Ingestion (soil, drinking water, food products: leafy vegetables and milk)}

The risk will be due to the ingestion of radium-226 present in soil, drinking water and food products such as cow's milk and leafy vegetables.

For contaminated soil, the route of exposure is via incidental soil ingestion. The expression to calculate this risk is given by $\left(\mathrm{R}_{\mathrm{Rsoil}, \text { ing }}\right)(\mathrm{Rood}, 2003)$ :

$$
\mathrm{R}_{\mathrm{Rsoil}, \text { ing }}=\mathrm{C}_{\text {soil }} \cdot \mathrm{U}_{\text {soili,ing }} \cdot \mathrm{RC}_{\text {soi, ing }} \cdot \mathrm{E}_{\mathrm{f}}(2)
$$

The necessary inputs to calculate the resulting risk are: soil concentration, $\mathrm{C}_{\mathrm{s}}=257 \mathrm{~Bq} / \mathrm{kg}$ (Pereira et al., 2004); soil ingestion rate (adult agriculture scenario) $\mathrm{U}_{\text {soil,ing }}=100 \mathrm{mg} / \mathrm{d}$ or $0,0001 \mathrm{~kg} / \mathrm{d}$ (Wise, 2004); risk coefficient for soil ingestion, $\mathrm{RC}_{\text {soil,ing }}=1,97027 \times 10^{-8} \mathrm{~Bq}^{-1}(\mathrm{EPA}, 1995)$ and exposure frequency, $\mathrm{E}_{\mathrm{f}}=87 \mathrm{~d} / \mathrm{year}$. The resulting annual cancer risk incurred by soil ingestion is $4,41 \times 10^{-8}$. For a long-term chronic ingestion of soil contaminated with radium-226 during 75 years (EPA 1997) the incremental lifetime cancer risk is $3,30 \times 10^{-6}$. This show that soil ingestion contaminated with radium does not pose any extra risk. Well water contaminated with radium-226 will pose a risk by ingestion based on the following scenario: all drinking water to the receptor is supplied by water taken from a well located hydrologically downgradient from the tailings pile. The expression to calculate this risk is given by (Rood, 2003):

$$
\mathrm{R}_{\mathrm{Rwater} \mathrm{,ing}}=\mathrm{C}_{\text {water }} \cdot \mathrm{U}_{\text {water ,ing }} \cdot \mathrm{RC}_{\text {water ,ing }} \cdot \mathrm{E}_{\mathrm{f}} \cdot \mathrm{f}_{\text {waler }}(3)
$$

Radium concentration in the well water is given by $\mathrm{C}_{\mathrm{w}}=0,4 \mathrm{~Bq} / \mathrm{L}($ Exmin, 2003); water ingestion rate, $U_{\text {water,ing }}=2 \mathrm{~L} /$ day $(E P A, 1997)$; risk coefficient for water ingestion, $\mathrm{RC}_{\text {water,ing }}=1,04054 \times 10^{-8} \mathrm{~Bq}^{-1}$ (EPA, 1995); the fraction of contaminated water used for drinking $\left(f_{\text {water }}\right)$ was assumed to be equal to 1 (i.e., all drinking water available for consumption at a site is potentially contaminated), thus, it was assumed that the receptor gets one hundred percent of their drinking water from groundwater; exposure frequency $\left(\mathrm{E}_{\mathrm{f}}\right)$ was set to 365 days per year, assuming that the receptor does not take any vacation time away from their homes ever. In case of a residential scenario it should be considered an exposure frequency of 350 days per year according to EPA Human Exposure Factors policy (EPA, 1997), assuming that residents take an average of 2 weeks' vacation time away from their homes each year.

The annual cancer risk incurred by water ingestion is $4,56 \times 10^{-6}$. For a long-term chronic ingestion of radium-226 during 75 years the incremental 
lifetime cancer risk is of $3,42 \times 10^{-4}$ which means an incremental risk of one in ten thousand.

Consumption of locally grown food products from small farms around the tailings and the mine may be contaminated with radium-226 by irrigation with contaminated water (from the well or from the streamlet) or by airborne particles from the tailings. It should be considered the consumption of vegetables (potatoes, tomatoes, carrots, etc.) and leafy vegetables (lettuce, cabbage, broccoli, etc.) grown in these farms but only leafy vegetables (mainly cabbage) were considered due to the available data. Milk consumption from farm cows was also considered. The risk resulting from the ingestion of contaminated leafy vegetables is (Rood, 2003):

$$
\mathrm{R}_{\text {Rveg,ing }}=\mathrm{C}_{\mathrm{veg}} \cdot \mathrm{U}_{\text {veg,ing }} \cdot \mathrm{RC}_{\mathrm{veg}, \text { ing }} \cdot \mathrm{E}_{\mathrm{f}} \cdot \mathrm{f}_{\mathrm{veg}}(4)
$$

Radium-226 concentration measured in leafy vegetables $\left(\mathrm{C}_{\mathrm{veg}}\right)$ was 21,9 $\mathrm{Bq} / \mathrm{kg}$ (Falcão et al., 2005); vegetation ingestion rate $\left(\mathrm{U}_{\text {veg,ing }}\right)$ was set to 0,175 $\mathrm{kg} / \mathrm{d}$ (Yu, 2001); risk coefficient for foodstuff ingestion $\left(\mathrm{RC}_{\text {food,ing }}\right)$ was considered to be $1,38919 \times 10^{-8} \mathrm{~Bq}^{-1}$ (EPA, 1995); exposure frequency $\left(\mathrm{E}_{\mathrm{f}}\right)$ was set to 365 days per year, as previously, and the fraction of ingested leafy vegetables from the farm products $\left(f_{\mathrm{veg}}\right)$ was set to 1 (all leafy vegetables consumption comes from the farm and are contaminated). The cancer risk incurred by contaminated leafy vegetables ingestion is $1,94 \times 10^{-5}$. For a longterm chronic exposure corresponding to an average life expectancy of 75 years, the incremental lifetime cancer risk is $1,46 \times 10^{-3}$ (EPA, 1997). This means an excess risk of one in one thousand.

Cow's milk contamination is due to both animal's ingestion (contaminated water, soil and pasture) and inhalation. The risk is estimated by the same expression as for leafy vegetables consumption with the following inputs: milk concentration, $\mathrm{C}_{\text {milk }}=0,029 \mathrm{~Bq} / \mathrm{L}$ (modeled for a similar contaminated site) (Dinis and Fiúza, 2007); milk ingestion rate, $\mathrm{U}_{\text {milk,ing }}=0,615 \mathrm{~L} / \mathrm{d}$ (EPA, 1997); risk coefficient for milk ingestion, $\mathrm{RC}_{\text {food,ing }}=1,38919 \times 10^{-8} \mathrm{~Bq}^{-1}$ (EPA, 1995); exposure frequency, $\mathrm{E}_{\mathrm{f}}=365 \mathrm{~d} /$ year and considering that all ingested milk comes from the farm cows and is contaminated, $\mathrm{f}_{\text {milk }}=1$. The annual cancer risk incurred by milk ingestion is $9,04 \times 10^{-8}$. For a long-term chronic exposure period of 75 years the incremental lifetime cancer risk is $6,78 \times 10^{-6}$. This value does not pose any extra risk incurred by the ingestion of milk contaminated with radium-226. The total incremental cancer risk incurred by the ingestion of contaminated soil, water, leafy vegetables and milk is $1,81 \times 10^{-3}$, which means an excess risk of one in one thousand mainly due to leafy vegetable ingestion and water ingestion. The total incremental lifetime risk cancer resulting from inhalation and ingestion is $2,72 \times 10^{-2}$. 


\subsubsection{Incremental Lifetime Cancer Risk Incurred by Chemical or Metal Exposure}

Arsenic present in drinking water from the water well was considered for this exposure pathway. Some authors reported that the health effects from ingestion of 1 to $2 \mathrm{mg} / \mathrm{kg} /$ day of inorganic arsenic result in nausea and vomiting followed by severe abdominal pain, bleeding in the gastrointestinal tract, and in some cases, death by renal failure (ATSDR, 2008). Levels of arsenic substantially above this level in current drinking water, if ingested daily over many years, could cause the chronic arsenic poisoning.

The incremental lifetime cancer risk incurred by a person ingesting contaminated water with arsenic is computed for a single carcinogenic chemical or metal by this expression (Rood, 2003):

$$
\mathrm{RC}_{\text {water ing }}=\mathrm{C}_{\text {water }} \cdot \mathrm{U}_{\text {water ing }} \cdot \frac{\mathrm{SF}_{\text {water }, \text { ing }}}{\mathrm{BW} \cdot \mathrm{AT}} \cdot \mathrm{E}_{\mathrm{f}} \cdot \mathrm{E}_{\mathrm{d}}(5)
$$

Arsenic concentration in well water, $\mathrm{C}_{\text {water }}=0,143 \mathrm{mg} / \mathrm{L}$ (Exmin, 2003); water ingestion rate, $\mathrm{U}_{\text {water,ing }}=2 \mathrm{~L} /$ day; cancer slope factor for arsenic ingestion in drinking water, $\mathrm{SF}_{\text {water,ing }}=1,5$ (kg.d) $/ \mathrm{mg}$ (IRIS, 2008); body weight, $\mathrm{BW}=$ $70 \mathrm{~kg}$; averaging time AT $=75$ years (or 25550 days, life expectancy); exposure frequency, $E_{f}=365$ days/year; exposure duration $E_{d}=30$ years. The incremental lifetime cancer risk for an individual who consumed $2 \mathrm{~L}$ of water per day at $0,143 \mathrm{mg} / \mathrm{L}$ of arsenic during 30 years is 0,002627 or $2,63 \times 10^{-3}$, which means an excess risk of one in one thousand.

\subsubsection{Noncarcinogenic Health Effects Incurred by Chemical or Metal Exposure}

Beryllium concentration in soil may lead to windborne or airborne particulates contaminated. Inhalation of beryllium may result in rhinitis, tracheobronchitis, pneumonitis and death due pulmonary edema or heart failure. It can mainly result into two types of respiratory disease, acute beryllium disease and chronic beryllium disease (berylliosis). Both forms can be fatal. Chronic beryllium disease results from breathing low levels of beryllium and is a type of allergic response. There can be a long latency period (up 25 years following exposure) prior to the onset of any symptoms. The health effects incurred by beryllium inhalation may be estimated by the expression (Rood, 2003):

$$
\mathrm{HQ}=\frac{\mathrm{C}_{\text {air }} \cdot B R \cdot E_{\mathrm{f}} \cdot E_{\mathrm{d}}}{\mathrm{R}_{\mathrm{f}} \mathrm{D}_{\text {inh }} \cdot \mathrm{BW} \cdot \mathrm{AT}}(6)
$$

Noncarcinogenic health effects are quantified in terms of hazard quotient (HQ) evaluated for a possible receptor exposed to beryllium by inhalation: an 
exposure scenario of 8 hours per day, 5 days per week, 52 weeks per year, corresponding to $87 \mathrm{~d} /$ year of exposure frequency $\left(\mathrm{E}_{\mathrm{f}}\right)$ to soil contaminated with beryllium was considered in this study. The other necessary inputs are: Beryllium concentration in air, $C_{\text {air }}=1,09 \times 10^{-5} \mathrm{mg} / \mathrm{m}^{3}$ (estimated from available data); breathing rate, $\mathrm{BR}=17,8 \mathrm{~m}^{3} / \mathrm{d}$; body weight $\mathrm{BW}=70 \mathrm{~kg}$; averaging time $\mathrm{AT}=75$ years or 25500 days; exposure frequency $\mathrm{E}_{\mathrm{f}}=87$ $\mathrm{d}$ /year; exposure duration $\mathrm{E}_{\mathrm{d}}=30$ years and the beryllium reference dose for inhalation $\left(\mathrm{R}_{\mathrm{f}} \mathrm{D}_{\text {inh }}\right)$ is $5,7 \times 10^{-6} \mathrm{mg} /(\mathrm{kg} . \mathrm{d})$ (EPA, 1995). The resulting hazard quotient to quantify the noncarcinogenic health effects incurred by beryllium inhalation is $\mathrm{HQ}=0,05$ which is inferior to one; the exposure to beryllium in this scenario does not pose any risk.

\section{Discussion and Conclusions}

The focus of this study was to exemplify how to apply a risk assessment in some of its components. More specifically it was intended to evaluate the potential impacts of current releases of hazardous substances from a contaminated site with uranium tailings and wastes during almost a period of 30 years. Several scenarios could have been adopted for different exposure pathways or routes of exposure. A life expectancy of 75 years was assumed to carcinogenesis effects. Radionuclide and chemical concentration in soil, air and groundwater, were needed along with parameters describing the exposure scenario. Radionuclide in leafy vegetables was measure but cow's milk concentration was modeled from pasture ingestion contaminated by soil, air and groundwater in an appropriate exposure scenario (Dinis and Fiúza, 2007).

The exposure pathways included in this risk assessment represent some of the exposure pathways that may be present in a contaminated site with radioactive materials and heavy metals; however is not an exhaustive list of potential exposure pathways.

From the results obtained it can be concluded that most of incremental lifetime cancer risk incurred by radionuclides exposure is due to indoor radon inhalation. In a risk management stage the risk manager could propose some mitigation measures to minimize the exposure and, in this way, decrease the risk. Some of these measures are easy to handle such as sealing cracks and other openings in the house's foundation, installing a vent pipe system and fan, which pulls radon from beneath the house and vents it to the outside (soil suction radon reduction system), promote ventilation (artificial or natural) inside the houses, specially in the lower floors and install continuous electronic radon monitors or alpha-track (ATD) detectors to control radon levels, making periodic long-term measurements to insure that the system continues to reduce the radon to acceptable levels. 


\section{References}

ATSDR (2008), Public Health Assessment, Monticello Mill Tailings (DOE) and Monticello Radioactively Contaminated Properties (aka Monticello Vicinity Properties). Online: http://www.atsdr.cdc.gov/HAC/PHA/monticel/mon_p2b.html.

Bettencourt A.O., Teixeira M.M., Elias M.D., Madruga M.J. (1990), Environmental Monitoring in Uranium Areas. In: Environmental Behaviour of Radium, Vol. 2. Technical Reports Series N. ${ }^{\circ} 310$, pp. 281-294, IAEA, Vienna.

Calewaert J.B. (2006), Environmental Risk Assessment for Pollution of Marine Activities. Adapted from Le Roy D., Volckaert A., Vermoote S., Wachter B., Maes F., Coene J. and Calewaert J.B., Risk Analysis of Marine Activities in the Belgian Part of the North Sea (RAMA). Research in the framework of the BELSPO Global Change, Ecosystems and Biodiversity, SPSDII, 107 pp. Online: http://www.encora.eu/coastalwiki/Main_Page.

Dinis M.L. and Fiúza A. (2005), Simulation of Liberation and Transport of Radium from Uranium Tailings, in: "Uranium in the Environment - Mining Impact and Consequences", pp 609 - 618. Broder J. Merkel; Andrea Hasche-Berger (Eds), 897 pp., Proceedings of the Congress: Uranium Mining and Hydrogeology IV, Freiberg, Germany, 11 - 16 September 2005, Springer publishers-ISBN 10 3-540-28363-3; ISBN 13 978-3-540-28368-8.

Dinis M.L. and Fiúza A. (2006), Modeling the Transport and Fate of Pollutants in the Environment: Soil, Water and Air, in "Chemicals as an Intentional and Accidental Global Environmental Threats”, pp. 469 - 476. Simeonov, Lubomir and Chirila, Elisabeta (Eds), Springer, XX, 514 pp., ISBN-10: 1-4020-5096-8; ISBN-13: 978-1-4020-5096-1.

Dinis M.L. and Fiúza A. (2007), Exposure assessment to radionuclides transfer in food chain, in: "Multiple Stressors: A Challenge for the Future", pags 309 - 323. Series: NATO Science for Peace and Security, Environmental Security. Mothersill, Carmel; Mosse, Irma; Seymour, Colin (Eds), Springer, 375 pp., ISBN: 978-1-4020-6334-3.

EPA, U.S. Environmental Protection Agency (1995), Health Effects Assessment Summary Tables (HEAST), Environmental Criteria and Assessment Office, Office of Health and Environmental Assessment, Office of Research and Development, Radionuclide Carcinogenicity Slope Factors: HEAST. Online: http://www.epa.gov/rpdweb00/heast/.

EPA, U.S. Environmental Protection Agency (1997), Exposure Factors Handbook, Office of Research and Development, EPA/600/P-95/002. Online: http://www.epa.gov/ncea/pdfs/efh/.

EPA, U.S. Environmental Protection Agency (1998), Human Health Risk Assessment Protocol for Hazardous Waste Combustion Facilities. Office of Solid Waste, EPA530-D-98-001A. Online: http://www.epa.gov/epaoswer/hazwaste/combust/risk.htm.

EPA, U.S. Environmental Protection Agency (1999), Cancer Risk Coefficients for Environmental Exposure to Radionuclides, Federal Guidance Report N. ${ }^{\circ}$ 13, EPA 402-R-99-001, Office of Radiation and Indoor Air. Online: http://www.epa.gov/radiation/docs/federal/402-r-99001.pdf.

EPA, U.S. Environmental Protection Agency (2007), Framework for Metals Risk Assessment, EPA 1205/R-07/001. Office of Science Advisor, Risk Assessment Forum. Online: http://www.epa.gov/osa/metalsframework/.

EXMIN (2003), Estudo Director de Áreas de Minérios Radioactivos - 2. ${ }^{a}$ fase. Companhia de Indústria e Serviços Mineiros e Ambientais, SA.

Fairman R., Mead C.D. and Williams W.P. (1998), Environmental Risk Assessment Approaches, Experiences and Information Sources. Published by European Environment Agency - EEA. Online: http://reports.eea.europa.eu/GH-07-97-595-EN-C2/en/riskindex.html. 
Falcão J.M., Carvalho, F.P., Leite M.R.M, Alarcão M., Cordeiro E., Ribeiro J., (2005): MinUrar, Minas de Urânio e seus Resíduos: Efeitos na Saúde da População, Relatório científico I, Publ. INSA, INETI, ITN.

IRIS (2008), Integrated Risk Information System (IRIS). http://cfpub.epa.gov/ncea/iris/index.cfm.

Nero J.M.G., Dias J.M.M., Pereira A.J.S.C., Neves L.J.P.F. and Torrinha J. (2005), Environmental evaluation and remediation methodologies of radioactive abandoned mines in Portugal. Proceedings of the "International Workshop on Environmental Contamination from Uranium Production Facilities and their Remediation, Lisbon, IAEA, pp. 145-158.

Pereira A.J.S.C., L.J.P.F. Neves J.M.M. Dias A.B.A., Campos \& S.V.T. (2004), Evaluation of the Radiological Hazards from Uranium Mining and Milling Wastes (Urgeiriça - Central Portugal), XI International Congress of the International Radiation Protection Association.

Rood A.S. (2003), Risk Analysis, Communication, Evaluation, and Reduction at LANL, Contemporary Risk Assessment Methodology, 9-RACER LANL-2003-DRAFT.

Wilcox R.L.T., Burrows M.C.D.R., Ghosh S. and Ayyub B.M. (2000), Risk-based Technology for the Safety Assessment of Marine Compressed Natural Gas Fuel Systems. International Cooperation on Marine Engineering Systems/The Society of Naval Architects and Marine Engineers. Paper presented at the 8th ICMES/SNAME, New York Metropolitan Section Symposium in New York, May 22-23, 2000.

WISE, World Information Service on Energy (2004), Uranium Radiation Properties. Online: http://www.wise-uranium.org/ruxfr.html.

Khan A.J. (2000), A study of indoor radon levels in Indian dwellings, influencing factors and lung cancer risks. Radiation Measurements 32(2000) 87-92.

Yu C., Zielen A.J., Cheng J.-J., LePoire D.J., Gnanapragasam E., Kamboj S., Arnis J., Wallo III A., Williams W.A., Peterson H., (2001), User's manual for RESRAD, version 6, ANL/EAD4. Environmental Assessment Division, Argonne National Laboratory, Illinois. 